\title{
First steps towards self-regulated learning
}

\section{Setting goals in MOOCs}

\section{Barbara Conde Gafaro}

\section{I Introduction}

I am up for something new. I don't want to be a dinosaur and I want to keep up with things, but I just needed a little bit of help to get started.

Irene, adult language learner

The COVID-19 pandemic has disrupted our way of learning and teaching. Lockdown measures implemented by governments to prevent the spread of the virus have changed our everyday life, including education. These measures have led most educators and learners to step into the world of online learning and opt for learning technologies to replace face-to-face learning environments. Although the work presented in Chapter 5 happened before COVID-19, this contribution's narrative is even more relevant at this time of the pandemic. Learners are expected to be equipped with strategies and study skills to chart a path for their sudden online education without having the constant supervision of an in-class teacher, which is similar to the cases discussed in this chapter.

These unprecedented circumstances have resulted in various opportunities as well as challenges. Learners have the option to assume a responsible role in their online education. When they take responsibility for their learning, they regulate their thoughts, feelings, and actions, i.e., learners become masters of their learning processes for attaining goals (Zimmerman, 2011). Employing self-regulatory processes and being aware of how these processes influence one's preparation and willingness to self-regulate are crucial steps in today's open world learning. For example, learners are anticipated to self-regulate their learning in Massive Open Online Courses (MOOCs) (Milligan \& Littlejohn, 2016), since "a MOOC is completely voluntary.You decide that you want to participate, you choose how to participate, then you participate" (Downes, 2012). However, taking part in such online courses becomes a challenge for those who cannot learn independently (Littlejohn \& Hood, 2018). Therefore, learners in order to fully benefit from their studies should be independent and know how to self-regulate to succeed in learning at a distance.

In foreign language education, MOOCs have been considered to support language learning at a distance (Gimeno-Sanz, 2021). These online courses provide 
opportunities for language learners to practise their target language, either by following courses that are designed to teach a language (LMOOCs) or by selecting MOOCs that are related to learners' interests so that they can study a language for specific purposes, see also Chapter 6 (Chua, 2022). Likewise, the pandemic has influenced a growing global demand for remote language learning. A recent review of MOOC stats and trends listed foreign language learning in the top ten of most popular subjects studied amidst the pandemic - with 815 language courses offered by the main providers at the time of writing (Class Central, 2021; Shah, 2020).Yet, the challenges that MOOCs represent for language learners remain underresearched (Gillespie, 2020; Sallam, Martín-Monje, \& Li, 2020). The challenge mentioned above about self-regulation in MOOCs is not much studied in relation to languages (Alonso-Mencía et al., 2020), especially the forethought processes that language learners are anticipated to adopt so that they can initiate their selfregulated learning in those online courses.

Hence, Chapter 5 aims to provide a deeper understanding of the forethought processes, with particular reference to goal setting and goal orientation. Both processes were employed by 19 adult language learners during four weeks of engagement with MOOCs as part of their classroom-based language courses. The findings from Chapter 5 may contribute to support learners' self-regulated learning and, last but not least, encourage learners to assume responsibility for their language education in which active learning is the new normal.

\subsection{Self-regulated learning}

Self-regulated learning (SRL) is conceptualised as a dynamic group of processes that learners employ to initiate, sustain, and assess their learning towards goal achievement. Zimmerman (1989) was one of the first to cover the aspect of metacognition in his triadic model of self-regulation. Metacognition refers to two clusters of activities, namely learners' self-awareness of how, when, and where to use different cognitive strategies and the regulation of those strategies that direct their learning (Flavell, 1979). Winne and Hadwin's (1998) SRL model also included this aspect of learning; however, it failed to consider the interaction of metacognitive processes with other motivational and social aspects of selfregulation (Greene \& Azevedo, 2007). This missing interplay evidenced in the latter was presented in a redefined SRL model posed by Zimmerman and Moylan (2009). They designed an integrative three-phase model to explain potential interactions among metacognitive and motivational processes that occur during learning efforts.

Zimmerman and Moylan's (2009) cyclical model of SRL introduces the notions of metacognition and motivation throughout a preparatory, a performance, and a reflective phase, described below:

1 Forethought Phase: it refers to learning processes and sources of motivation that are contemplated in preparation for efforts to learn and affect learners' willingness to self-regulate their learning. 
2 Performance Phase: it involves processes that are employed during efforts to learn and influence learners' self-control and self-monitoring of their performance.

3 Self-reflection Phase: it refers to processes that follow efforts to learn and subsequently influence learners' reflection and affective reactions to that learning experience. "These self-reflections, in turn, influence forethought regarding subsequent learning efforts, which completes the self-regulatory cycle".

(Zimmerman \& Moylan, 2009, p. 301)

The three self-regulatory phases are composed of 20 metacognitive processes and sources of motivation. However, this chapter's scope focuses only on the processes of goal setting and goal orientation included in the forethought phase. The forethought phase consists of two main categories: task analysis processes and selfmotivation sources. In the first category, learners are anticipated to unpack a learning task, set educational goals, and outline a strategy to be prepared for the task and its environmental setting. Goal orientation is part of the second category and reflects learners' beliefs about the purposes of engaging in learning or performing tasks (Zimmerman \& Moylan, 2009).

The SRL cyclical model places goal setting at the top of the learning processes that learners are anticipated to deal with in the forethought phase. Setting goals enables learners to initiate their learning and monitor their progress towards those goals and adjust their learning, if necessary (Zimmerman, 2000). There are two types of goals identified in the socio-cognitivist literature: distal (long-term) goals and proximal (short-term) goals. Several studies show that setting proximal goals is more effective than focusing on distal goals (Zimmerman, 2008). The most effective proximal goals are challenging for learners, specific to the task, and align with other goals (Zimmerman, 2008). Altogether, research suggests that learners should set specific outcomes in time, either driven by learning or performance-oriented goals, to learn more effectively on their own. The following section expands on the importance of goal setting in flexible learning environments by covering works that examine successful learning in MOOCs.

\subsection{MOOCs and goal setting}

MOOCs appeared in online education when Siemens, Downes, and Cormier facilitated a way of learning in the networked world to a total of 2,200 people via an online course called "Connectivism and Connective Knowledge (CCK08)" (Downes, 2009). MOOCs have continued to provide large-scale participation and access to subjectspecific resources via the web since then. In the case of LMOOCs, these have been designed for anybody interested in learning particular aspects of a foreign language due to the limited time they are offered, between four and six weeks (Gimeno-Sanz, 2021).

Although MOOCs represent the growth of online learning delivered at a massive scale, their principle of open access to learning for everyone has been questioned (Littlejohn \& Hood, 2018), and subsequently, their commitment to open 
world learning. MOOCs welcome people worldwide to access online education content without any academic prerequisite needed. However, the access to discussion forums (Chua, 2022), multimedia material, and quizzes offered in those courses is limited to people who can learn independently; see also Chapter 8 (Rizvi et al., 2022) and Chapter 9 (Iniesto et al., 2022).

MOOC learners have the advantage of choosing their learning path (instructorpaced or self-paced online courses), managing the resources they want to cover, and the time they want to invest in the course materials (Beaven, 2013). However, such flexible learning approach embedded in the design of MOOCs might only favour "those who are able to self-regulate their learning, leaving the most disadvantaged behind" (Littlejohn \& Hood, 2018, p. 31). By way of illustration, learners who have formal academic qualifications typically enrol in and complete MOOCs at relatively higher rates (Kizilcec, Saltarelli, Reich, \& Cohen, 2017). Similarly, university students with a master's degree or $\mathrm{PhD}$ often report higher levels of goal setting, strategic planning and task strategies than people with lower qualifications enrolled in MOOCs (Kizilcec, Pérez-Sanagustín, \& Maldonado, 2017). Therefore, SRL becomes a crucial tool kit for learners who want to access online educational content and achieve success within such learning environments.

Likewise, Gimeno-Sanz (2021, p. 53) also argues that in most cases, MOOC learners "have to self-regulate their learning, very much relying on cognitive and resource management strategies". Goal setting is one of the self-regulatory processes employed by successful learners in those online courses. A recent study that surveyed 643 MOOC learners found that "MOOC completers reported significantly higher use of the goal-setting SRL subprocess than did MOOC noncompleters" (Handoko et al., 2019, p. 50). The findings are aligned with previous studies that identified goal setting as a common metacognitive process among successful learners in MOOCs (Kizilcec, Pérez-Sanagustín, \& Maldonado, 2017; Milligan \& Littlejohn, 2016). These studies examined the types of goals (proxi$\mathrm{mal} /$ distal) and how they influenced learning in MOOCs related to educational technology and STEM subjects. However, little is known about how learners set goals in LMOOCs or specific content-based MOOCs, particularly when preparing to work on these online courses as part of their classroom-based language courses. This gap in the literature raises the question of how language learners set their goals when engaging with MOOCs to support their classroom-based language education, and that was the main aim of the empirical study reported in this chapter.

\subsection{Research methods}

The empirical study described in this chapter was framed within a multiple-case study research. A case study examines a contemporary phenomenon in depth and within its real-world context (Yin, 2018). The phenomenon, also commonly known as the case, can involve persons, events, or decisions (Thomas, 2011). A multiple-case study comprises two or more cases to gain a detailed understanding of a situation. Examining multiple cases also contributes to having richer and more 
rigorous findings than the ones obtained solely based on a single case. Hence, conducting a multiple-case study was suited to capture the complexity of learners' goal-setting processes in MOOCs based on different language learners' experiences. As explained by Thomas (2011, p. 513), case studies can be "studied holistically by one or more methods". The design of the multiple-case study reported in this chapter employed multiple research methods that included three quantitative and qualitative instruments:

1 Four weekly monitoring surveys (WSURV1/2/3/4), with mostly openended questions, administered during each week of engagement with the MOOCs. The second question in the WSURV (what was your learning goal for this week?) allowed the researcher to delve into the type of goals participants set for the online courses.

2 An online SRL questionnaire (SRLQ) sent in week five of the project to survey participants' SRL processes. The SRLQ consisted of 29 items in total, but this chapter focused only on the first three that dealt with goal setting processes (1. I set specific short-term (daily or weekly) learning goals for the MOOC I chose. 2. I set specific long-term learning goals (monthly or for the whole MOOC). 3. I set realistic deadlines for learning in the MOOC.). The study did not aim to compare participants' SRL processes before and after their engagement with the MOOCs. Thus, the questionnaire was only administered at the end of the learning process.

3 A semi-structured interview (INV) conducted at the end of the project to probe participants' forethought processes of goal setting and goal orientation in their online courses.

The SRLQ was adapted based on the Motivated Strategies for Learning Questionnaire (Pintrich et al., 1991) and the INV was an alteration of an interview designed by Littlejohn and Milligan (2015). The research design of a multiple-case study follows a "replication logic", i.e., cases replicate the exact conditions of the first case to predict similar or contrasting results based on anticipated reasons (Yin, 2018). The extent of the replication logic presented in this chapter involved the exact three instruments to collect data in each case. The cases also shared the following conditions: small groups of adult language learners attending face-to-face language courses while engaging with MOOCs for a month to enhance that classroom-based instruction. The learners within those groups were the cases in this multiple-case study research.

Specific characteristics were considered within the selection criteria of the cases. The researcher contacted gatekeepers who run language courses for adult learners and included independent learning and/or interactive technologies as part of their syllabi. The 19 participants, who voluntarily joined the multiple-case study research, were learning languages for different purposes in two different contexts. In Case study 1, ten participants were taking face-to-face language courses in Spanish, Italian and French at a community learning centre in Milton Keynes (UK). The gatekeeper in Case study 1 regularly asked learners to complete a learning plan and 
record of achievement where they had to write their learning goals and marked if those were achieved by the end of the course. In Case study 2, nine participants were taking an English for academic and professional purposes course (ESP) offered as part of a local association in Ferrara (Italy). The gatekeeper contacted in Case study 2 usually asked students to use MOOCs within her ESP lessons to work on their motivation and academic performance. The gatekeepers' familiarity with the study's core ideas, goal setting processes and MOOCs, diminished accessibility issues in the recruitment process.

All participants were asked to engage with a MOOC of their choice, since students who find personal interests in a learning task are more likely to regulate their learning (Zimmerman, 2000). They were asked to use Class Central, a search engine tool to browse MOOCs by subjects and providers. Whereas learners in Case study 1 selected LMOOCs that suited their intermediate language proficiency level and personal interests, learners in Case study 2 chose specific contentbased MOOCs that matched their disciplinary specialisms and advanced language proficiency level. At the start of the project, the former self-reported a lower language proficiency level than the latter. This advantage in terms of language expertise enabled the ESP learners to select their MOOCs from a wide range of online courses that moved beyond the linguistic content usually offered in LMOOCs. Once participants selected their courses, they were free to decide how and when to work with the online material, though a minimum of two hours of study per week was suggested. They were also given pseudonyms, whose initial letter indicated which of the languages they were studying.

A substantial critique of case study research is that cases are not sampling units; hence, they cannot be generalisable. This perceived limitation can be addressed by connecting the case study to a theory so that "analytic generalisations" can be made, i.e., expanding theories at a higher conceptual level rather than extrapolating probabilities with "statistical generalisations" (Yin, 2018). Therefore, the researcher identified and classified learners' goal setting and goal orientation processes following a deductive approach within the qualitative data analysis based on Zimmerman and Moylan's (2009) forethought processes. The qualitative information was triangulated with the responses from the SRLQ to answer the question raised in this chapter. Altogether, the study's research design used three instruments to establish a chain of evidence concerning the goal setting and goal orientation processes that 19 participants in two case studies employed while engaging with MOOCs during four weeks of their face-to-face language courses.

\subsection{Results}

\subsection{Goal setting of community-based language learners (Case study I)}

Participants were asked to reflect on their goals in the second question of the weekly monitoring surveys (WSURV), in which they had to write down the learning goal for each week of their LMOOC-based learning. All ten participants set goals that 
covered the revision of grammar topics, vocabulary learning and the mastery of language skills (mainly listening skills). Another common pattern found around goal setting was learners' preferences for specific proximal goals. Figure 5.1 indicates a preponderance of specific-short term goals' over specific long-term goals among participants.

Based on the responses from the SRLQ illustrated below, six out of ten participants reportedly set specific short-term goals rather than specific long-term goals when working with their LMOOCs. Figure 5.1 also shows that most learners claimed to have set specific short-term goals alongside realistic deadlines for learning in their LMOOCs. The element of time is crucial when setting specific and achievable learning goals. Unfortunately, there was not much evidence in the qualitative data that showed learners formulating specific and time-limited goals during their LMOOC-based learning.

Despite the lack of realistic goals observed in the qualitative data of Case study 1, learners often elaborated multiple goals as part of their LMOOC experience. Eight out of ten participants set numerous targets during the four weeks of online learning. Most of them were targeting two different aspects of language, and others even reported having three goals in one of the weeks. By way of illustration, a learner of Italian said in the third weekly survey that she wanted to "revise the perfect tense of reflexives [sic] [verbs] and broaden my vocabulary plus continue to practise my listening" (WSURV3-Irene). The variety of goals set up by community-based learners reflected the different aspects of language they dealt with while engaging with the activities and audio-visual content offered in the LMOOCs.

Regarding participants' goal orientations, they reported having goals oriented towards learning linguistic and sociocultural topics and language skills development. Almost all their goals were mastery-oriented goals aimed at revising an

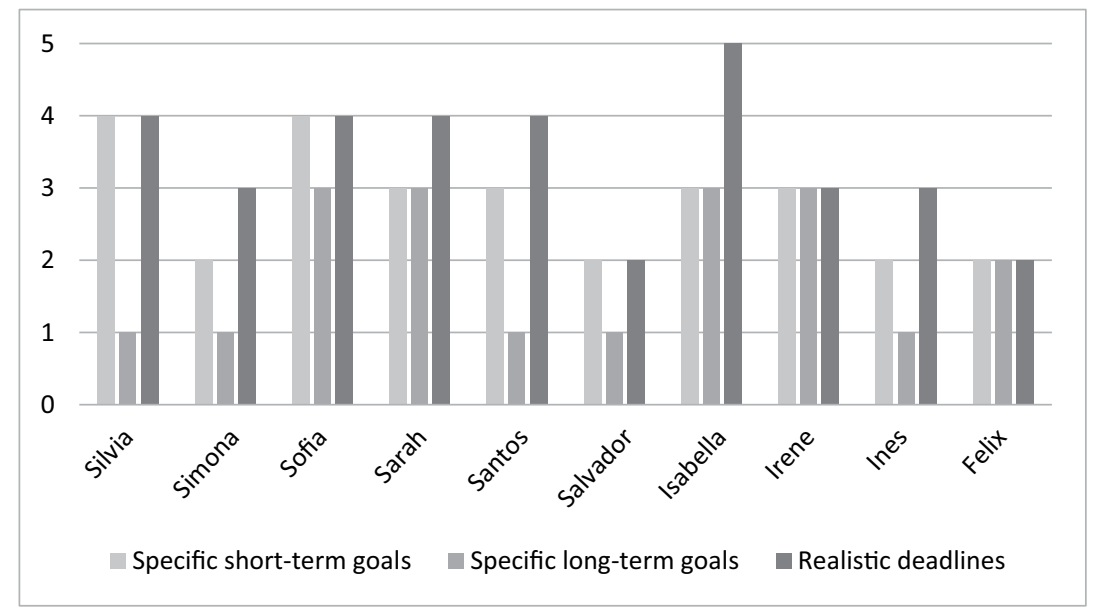

Figure 5.I Type of goals reported by community-based learners in their LMOOCs (Likert Response I-5). 
Table 5.I Comparison between mastery-oriented goals and performanceoriented goals set by community-based learners

\begin{tabular}{ll}
\hline Mastery-oriented goals & Performance-oriented goals \\
\hline - "Practise with tenses" & - "to get as many chapters finished" \\
(WSURV4-Salvador) & (WSURVI-Silvia) \\
- "to revise reflexive verbs" & "To complete the first week with \\
(WSURV2/3-Irene) & FutureLearn out and about" \\
- "No more listening" & (WSURVI/2/3/4-Sofia) \\
(WSURV2/3-Simona). & - "To complete week I of the structured \\
- "I need to improve my & course" (WSURVI/2/3/4-Sarah). \\
pronunciation" & - "Complete module one about plans" \\
(WSURV3-Sarah) & (WSURVI-Santos) \\
- "Improve my grammar" & - "spend more time [on task]" \\
(WSURV3-Felix) & (WSURV3-Isabella) \\
\hline
\end{tabular}

element of grammar, language skills improvement or learning about everyday spoken vocabulary/specific sociocultural content. Nevertheless, six out of ten participants also self-reported performance-oriented goals focused on LMOOC completion or performing well in the online course tasks, as illustrated in Table 5.1.

Learners who often reported specific performance-oriented goals appeared to set more realistic deadlines than learners who included mastery-oriented goals as part of their online learning experience. For example, Sofia and Sarah set clear goals that focused on completing the four weeks of the MOOC (Table 5.1); both learners also scored high in the third SRLQ item that measured realistic goal setting (Figure 5.1). Conversely, Salvador and Felix, who tended to set masteryoriented goals (Table 5.1), presented a low score in the last item of that questionnaire (Figure 5.1). One of the learners' mastery-oriented goals reported in week four of their online learning, "vocab-pronunciation. Verbs in the past tenses" (WSURV4Salvador), implied some work on the aspects of vocabulary, pronunciation, and grammar. However, such work remained unclear and possibly intangible, since it did not target a specific outcome to be achieved at a particular point in time. The wording of most proximal mastery-oriented goals revealed a vague idea of what learners wanted to attain within a specific time limit, questioning the realistic nature of these goals that focused on learning rather than performing well in an LMOOC.

\subsubsection{Goal setting of ESP learners (Case study 2)}

The nine ESP learners self-reported more proximal goals than distal ones when they engaged with specific content-based MOOCs. Most of their self-reported goals identified in their four weekly surveys had a clear focus, such as "writing a report (one page)" (WSURV4-Elton) or "understanding the deception [MOOC topic]" (WSURV3-Erik). A few learners self-reported distal goals that usually included future work beyond their MOOCs. For example, Ethan concluded by the end of week one: "I think that I should speak a lot: I have already a B2 level and it 
means I could improve speaking with native speakers. I think it would be the best thing I could do" (WSURV1-Ethan). Likewise, Edwin aimed to use formal expressions "in a more proper and more conscious way in the future" (WSURV3-Edwin). The main pattern of setting clear proximal targets for learning in the MOOCs was also evident in the SRLQ responses, as indicated in Figure 5.2.

Half of the learners in Case study 2 favoured proximal goals within their online learning experience, based on the responses from the SRLQ illustrated below. Meanwhile, those learners who reported specific distal goals typically formulated targets that extended beyond the work with their MOOCs, as previously stated by Edwin and Ethan. Most learners also claimed to have realistic deadlines for their engagement with specific content-based MOOCs (Figure 5.2). Nevertheless, they did not specify time-limited goals when completing the WSURV or taking part in the INV.

Concerning goal orientations, ESP learners reported setting mastery-oriented goals that focused on language skills improvement. All nine participants set goals aimed at developing receptive and productive language skills. Six out of nine participants also deployed goals that involved learning about the content of their MOOCs. For example, participant Elsa explained that her "main aim was to understand the basics of that course... how data works and how I can use them in my job" (INV-Elsa). Another participant also stressed that "I needed to improve my English competencies, skills, but I also needed to understand what the MOOC talked about" (INV-Erik). The mastery-oriented goals for almost half of the participants were twofold: strengthening their target language for academic/professional purposes and understanding the MOOC content, which they chose based on their specific area of knowledge.

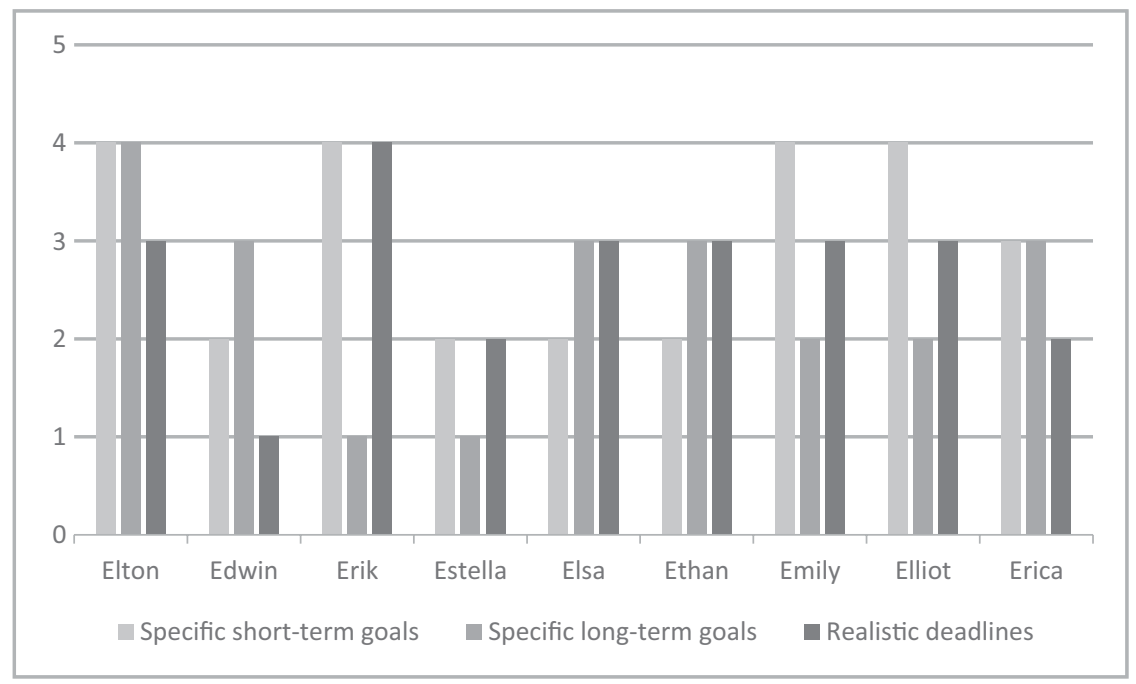

Figure 5.2 Type of goals reported by ESP learners in their MOOCs. 
A few participants also set performance-oriented goals while following their MOOCs. Four out of nine learners focused on completing the online courses or outperforming their prior language performance. Elliot, for example, wanted "to test my English with a topic I am familiar with" (WSURV1-Elliot). Similarly, Elton aimed at "writing more and better letters, articles and other English texts" (WSURV2-Elton) after working on his writing skills in week one of the MOOC. Although some learners' goals oscillated between performance and masteryoriented targets, ESP learners commented most frequently on pursuing masteryoriented goals than performance-oriented ones in the weekly surveys and semi-structured interview responses.

\subsection{Discussion and moving forward}

Chapter 5 addressed the goal setting and goal orientation processes employed by 19 adult language learners in two case studies to chart their learning path in selected MOOCs. Findings have shed light on how adult learners set goals over four weeks of engagement with MOOCs to support their classroom-based language learning, including the type of goals, goal-oriented preferences, and common difficulties when setting clear targets. Most learners in both case studies reported setting more proximal goals than distal goals. They also recorded more mastery-oriented goals than performance-oriented ones in their chosen online courses. However, it was difficult for participants to specify time-limited goals when initiating their self-regulated learning in MOOCs.

Community-based language learners and ESP learners formulated more shortterm goals in their LMOOCs and specific content-based MOOCs, respectively. This preference for proximal goals was arguably linked to the delivery mode of the online courses, which was described in the platforms that offered the MOOCs. There were not many instructor-paced courses available when conducting this study, so most participants selected self-paced online courses, i.e., no start or end date and less supervision by educators. "This delivery mode affects the way enrolees work in the course, fostering the establishment of short-term goals (which are not necessarily self-defined) that allow learners to persist in the MOOC" (AlonsoMencía et al., 2020, p. 327). The number of weeks in a MOOC and the way content is delivered (whether the material is released gradually or from the beginning) affect how learners deploy different strategies to self-regulate their learning process (Ferguson et al., 2015). Hence, setting proximal goals was a self-regulatory process employed by participants to cope with the self-paced learning in selected shortterm MOOCs.

All participants also preferred pursuing mastery-oriented goals over performanceoriented ones in their chosen online courses. Most learners were not planning on completing their MOOCs or obtaining certificates as an outcome of this online learning experience. They were formulating goals oriented towards revising specific aspects of the language, learning about subjects that were meaningful to them, and practising their language skills while covering the audio-visual material. In common with others (Beaven, 2013; Gimeno-Sanz, 2021), all participants found 
opportunities to revise their linguistic knowledge and practise their language skills by studying different topics in the target language.

Nevertheless, participants' learning goals were not very explicit concerning the outcomes they wanted to achieve at a particular point in time. Although they claimed to have set realistic deadlines, they did not include a specific time when formulating their goals. Not all learners may find the need to set a specific goal in a MOOC, particularly if they opt for relying on "predetermined objectives, rather than learner-defined goals" (Littlejohn \& Hood, 2018, p. viii). However, "goal setting produces an explicit feedback loop that requires self-evaluation on a specific time" (Zimmerman \& Moylan, 2009, p. 302). Thus, this lack of realistic deadlines evidenced in both cases may become an obstacle for learners when attempting to fulfil goals focused on learning and skills development in self-paced MOOCs.

This multiple case study suits the COVID-19 era, which has led most learners into an open world learning where they are anticipated to employ effective strategies to sustain their education at a distance. The findings have indicated that language learners can engage in goal setting processes when studying beyond the classroom in an LMOOC or a specific content-based MOOC, at least within the context of this study. Participants formulated outcomes they wanted to attain while learning independently in such online courses. However, they did not include time-bound goals, which raises questions about the realistic and achievable nature of the outcomes they set for their MOOC-based learning. The online learning experience described in Chapter 5 can count as the first steps towards SRL. Yet, learners still need to overcome various obstacles, such as setting vague and unrealistic goals, to initiate their self-regulation in the face of adversity.

\subsection{Implications for practice}

It is crucial for educators and learners to identify how learners set and assess their goals when learning independently. Researchers and educators need to understand and facilitate goal-setting processes beyond the classroom, especially the selfevaluation of outcomes on a specific time. Educators can take advantage of the MOOCs' potential for independent learning to encourage learners to initiate their self-regulated learning. Clear guidelines on setting specific, realistic, measurable, and attainable goals should be incorporated into those initiatives so that learners can effectively self-regulate their learning in an open world.

\section{References}

Alonso-Mencía, M.E., Alario-Hoyos, C., Maldonado-Mahauad, J., Estévez-Ayres, I., PérezSanagustín, M., \& Delgado Kloos, C. (2020). Self-regulated learning in MOOCs: lessons learned from a literature review. Educational Review, 72(3), 319-345. doi:10.1080/001319 11.2019.1566208

Beaven, A. (2013). Using MOOCs in an academic English course at university level. In A. Beaven, A. Comas-Quinn, \& B. Sawhill (Eds.), Case studies of openness in the language classroom (pp. 217-227). Research-publishing.net. Retrieved from https://doi.org/10.14705/ rpnet.2013.9781908416100 
Class Central. (2021). Language Learning Courses. Retrieved from https://www.classcentral.com/subject/language-learning

Chua, S. M. (2022). Discourse practices in MOOC discussions: a corpus linguistic approach. In B. Rienties, R. Hampel, E. Scanlon, \& D. Whitelock (Eds.), Open world learning: research, innovation and the challenges of high-quality education (pp. 76-88). London: Routledge.

Downes, S. (2012, March 1). What a MOOC does. [Web log post]. Retrieved from http:// www.downes.ca/post/57728

Downes, S. (2009, April 25). New technology supporting informal learning [Web log post]. Retrieved from https://halfanhour.blogspot.co.uk/2009/04/new-technologysupporting-informal.html

Flavell, J. H. (1979). Metacognition and cognitive monitoring: a new area of cognitivedevelopmental inquiry. American psychologist, 34(10), 906-911. doi: 10.1037\% 2F0003-066X.34.10.906

Ferguson, R., Clow, D., Beale, R., Cooper, A. J., Morris, N., Bayne, S., \& Woodgate, A. (2015). Moving through MOOCS: pedagogy, learning design and patterns of engagement. In G. Conole, T. Klobucar, C. Rensing, J. Konert, \& E. Lavoue (Eds.), Design for teaching and learning in a networked world (pp. 70-84). Lecture Notes in Computer Science Springer International. doi:10.1007/978-3-319-24258-3_6

Gillespie, J. (2020). CALL research: where are we now? ReCALL 32(2), 127-144. doi:10.1017/S0958344020000051

Gimeno-Sanz, A. (2021). LMOOCs: free, self-access language learning on a global scale. In T. Beaven \& F. Rosell-Aguilar (Eds), Innovative language pedagogy report (pp. 49-55). Research-publishing.net. doi: org/10.14705/ rpnet.2021.50.1235

Greene, J. A., \& Azevedo, R. (2007). A theoretical review of Winne and Hadwin's model of self-regulated learning: new perspectives and directions. Review of Educational Research 77, 334-372. doi: 10.3102/003465430303953

Handoko, E., Gronseth, S. L., McNeil, S. G., Bonk, C. J., \& Robin, B. R. (2019). Goal setting and MOOC completion: a study on the role of self-regulated learning in student performance in massive open online courses. International Review of Research in Open and Distributed Learning, 20(3), 39-58. doi: 10.19173/irrodl.v20i4.4270

Iniesto, F, McAndrew, P., Minocha, S., \& Coughlan, T. (2022). Accessibility in MOOCs: the stakeholders' perspectives. In B. Rienties, R. Hampel, E. Scanlon, \& D. Whitelock (Eds.), Open world learning: research, innovation and the challenges of high-quality education (pp. 119-130). London: Routledge.

Kizilcec, R. F., Saltarelli, A. J., Reich, J., \& Cohen, G. L. (2017). Closing global achievement gaps in MOOCs. Science, 355(6322), 251-252. doi: 10.1126/science.aag2063

Kizilcec, R. F., Pérez-Sanagustín, M., \& Maldonado, J. J. (2017). Self-regulated learning strategies predict learner behavior and goal attainment in Massive Open Online Courses. Computers \& Education, 104,18-33. doi: 10.1016/j.compedu.2016.10.001

Littlejohn,A. \& Hood, N. (2018). Reconceptualising learning in the digital age: the [un]democratizing potential of MOOCs. Gateway East, Singapore: Springer.

Littlejohn, A., \& Milligan, C. (2015). Designing MOOCs for professional learners: tools and patterns to encourage self-regulated learning. eLearning Papers, 42, 38-45. ISSN: 1887-1542

Milligan, C., \& Littlejohn, A., (2016). How health professionals regulate their learning in massive open online courses. The Internet and higher education, 31, 113-121. doi: 10.1016/j. iheduc.2016.07.005 
Pintrich, P. R., Smith, D. A. F., Garcia, T., \& McKeachie,W. J. (1991). A manual for the use of the motivated strategies for learning questionnaire (MSLQ). The Regents of The University of Michigan, (91-B-004). https://files.eric.ed.gov/fulltext/ED338122.pdf

Rizvi, S., Rienties, B., Kizilcec, R., \& Rogaten, J. (2022). Culturally adaptive learning design: a mixed-methods study of cross-cultural learning design preferences in MOOCs. In B. Rienties, R. Hampel, E. Scanlon, \& D. Whitelock (Eds.), Open world learning: research, innovation and the challenges of high-quality education (pp. 103-116). London: Routledge.

Sallam, M., Martín-Monje, E. \& Li,Y. (2020). Research trends in language MOOC studies: a systematic review of the published literature (2012-2018). Computer Assisted Language, 1-28. doi: 10.1080/09588221.2020.1744668

Shah, D. (2020, August 16). By the numbers: MOOCs during the pandemic. [Web log post]. Retrieved from https://www.classcentral.com/report/mooc-stats-pandemic/

Thomas, G. (2011). A typology for the case study in social science following a review of definition, discourse, and structure. Qualitative Inquiry 17(6), 511-521. doi: 10.1177/ 1077800411409884

Winne, P. H., \& Hadwin, A. F. (1998). Studying as self-regulated learning. In D. J. Hacker, J. Dunlosky, \& A. Graesser (Eds.), Metacognition in educational theory and practice (pp. 277-304). Hillsdale, NJ: Lawrence Erlbaum.

Yin, R. K. (2018). Case study research and applications: design and methods. Thousand Oaks, CA: Sage Publications.

Zimmerman, B.J. (2011). Motivational sources and outcomes of self-regulated learning and performance. In B.J. Zimmerman \& D.H. Schunk (Eds.), Handbook of self-regulation of learning and performance (pp. 49-64). New York: Routledge.

Zimmerman, B. J., \& Moylan, A. R. (2009). Self-regulation: where metacognition and motivation intersect. In D. J. Hacker, J. Dunlosky, \& A. C. Graesser (Eds.), Handbook of metacognition in education (pp. 299-315). New York: Routledge.

Zimmerman, B. J. (2008). Goal setting: a key proactive source of academic self-regulation. In D. H. Schunk \& B. J. Zimmerman (Eds.), Motivation and self-regulated learning: theory, research, and applications (pp. 267-295). New York: Erlbaum.

Zimmerman, B. J. (2000). Attaining self-regulation: a social cognitive perspective. In M. Boekaerts, M. Zeidner, \& P. Pintrich (Eds.), Handbook of self-regulation (pp. 13-39). San Diego, CA:Academic Press.

Zimmerman, B. J. (1989). A social cognitive view of self-regulated academic learning. Journal of Educational Psychology 81, 329-339. doi: 10.1037/0022-0663.81.3.329 